\title{
EFFECTS OF TAMOXIFEN AND AROMATASE INHIBITORS ON ENDOMETRIUM IN BREAST CANCER PATIENTS AT ZAGAZIG UNIVERSITY HOSPITALS.
}

\author{
Ahmed A.Amer; Nashwa E. Nawar; Amr A. Elnemr; Manal A.Abd Elmageed M \\ Obstetrics and Gynecology Departments, Faculty of medicine, Zagazig University.
}

Corresponding author:

Manal A. Abd Elmageed, theprofmenna@gmail.com.
Objective: To investigate the effect of endometrial abnormalities in breast cancer patients treated with Tamoxifen (group I), Aromatase inhibitors (group II) or No treatment (group III) .To determine the best approach for screening these patients for endometrial pathology. Methods:117 patients at outpatient clinic, Departments of Clinical Oncology\& Nuclear medecine and of Obstetrics \& Gynecology, Zagazig University Hospitals .Conventional transvaginal ultrasonography for detection of the uterine size, endometrial thickness as basal ultrasound and followed up every six months. Diagnostic hysteroscopy and endometrial biopsy were done only for patients with abnormal uterine bleeding and asymptomatic patients with increasd endometrial thickness $>5 \mathrm{~mm}$ in postmenopausal or $>8 \mathrm{~mm}$ in premenopausl cases . Results: At the end of 48 months follow up period, the most common endometrial lesions of group I were endometrial hyperplasia in 5 patients $(31.3 \%)$,endometrial polyp in 4 patients $(25 \%)$ and endometrial atrophy in two patient (12.5\%). This gave impression that endometrial poylp \& endometrial hyperplasia were the most common endometrial lesion of group I. In group II the most common endometrial lesions detected by hysteroscopy and histopathological examination were endometrial atrophy in 3 patients (30\%), endometrial polyp in one patient $(10 \%)$ and endometrial hyprplasia in one patient $(10 \%)$. Conclusions: Tamoxifen was associated with development of various endometrial changes, including endometrial hyperplasia, cystic atrophy, leiomyoma, endometrial carcinoma and other types of uterine malignancy especially in postmenopausal patients. Even if they are asymptomatic, these patients must be evaluated carefully

\section{INTRODUCTION}

B reast cancer is the most frequently diagnosed cancer in women and the second most frequent cause of cancer mortality in United States. Breast cancer represents a major health problem, with more than $1,000,000$ new cases and 370.000 deaths yearly worldwide (1).

The standard treatment of early breast cancer is surgery, with or without radiotherapy and chemotherapy, followed by hormonal therapy for women with hormone receptorpositive tumor. The use of adjuvant Tamoxifen has significantly improved disease free survival (DFS) and overall survival (OS). However even in women taking Tamoxifen for 5 years, more than half of breast cancers relapse between 5 and 15 years. Primary resistance to tamoxifen has been observed in some patients, and those patients who may have initially benefited from tamoxifen can develop secondary resistance (2).

It is also important to consider that although tamoxifen has been shown to have positive effects on bone and lipid metabolism, it has also been associated with an increased risk of endometrial cancer and thromboembolism (3)

However, the third-generation aromatase inhibitors (AIs) are now playing an increasingly important role for endocrine therapy, based on growing clinical evidence of their benefit (4). The third-generation AIs, anastrozole and letrozole (nonsteroidal) and exemestane (steroidal), have established superior efficacy versus tamoxifen, as first-line treatment of metastatic breast cancer in postmenopausal patients (5).

These agents have also shown a benefit in efficacy over tamoxifen as adjuvant endocrine therapy in postmenopausal patients with 
hormone receptor-positive early breast cancer. AIs can be utilized in several adjuvant settings: starting with an AI (upfront therapy), switch to an AI after 2-3 years of tamoxifen, or extended therapy with an AI following 5 years of tamoxifen. All of these strategies are potentially useful dependent upon individual patient, tumour characteristics, and treatment goals (6).

The aim of the study is to detect the effect of Tamoxifen (TMX), Aromatase inhibitors (AIS) or no adjuvant treatment (NT) on endometrium in breast cancer patients and to determine the best approach for screening these patients for endometrial pathology.

\section{PATIENTS AND METHODS}

This is a comparative cross sectional study conducted in the outpatient clinics of the departments of Clinical Oncology\& Nuclear medicine, and of Obstetrics \& Gynecology, Zagazig University, during the period from August 2014 till August 2018. This study was approved by the Institutional Review Board (IRB), Zagazig University. All the included cases gave informed consents.

\section{Patients were classified into three groups:}

1. Tamoxifen (group I): received tamoxifen at a daily dose of $20 \mathrm{mg}$, for last 6 months.

2. Aromatase inhibitors (group II): received letrozole administered at a daily dose of $2.5 \mathrm{mg}$ or anastrazole administrated at a daily dose of 1 $\mathrm{mg}$, for 6 months. This group involved patients shifted to AIS after treatment with tamoxifen due to TMX effect on endometrium.

3. No adjuvant hormonal treatment or Control group (group III)): which had no ER and PR receptors .

\section{Operational Design:}

All selected patients were subjected to:

$1^{\text {st }}$ visit:

1. A written informed consent was taken.

2. Full history taking including - family history of any malignancy, general cause of bleeding or presence of abnormal vaginal bleeding).

3. General examination including vital signs, BMI, chest, heart, and abdominal examination.

4. Pelvic examination to exclude pelvic pathology and local causes of vaginal bleeding and ultrasound.

5. Transvaginal ultrasound.

* Follow up visit every 6 months :

1. Transvaginal ultrasound.
2. Diagnostic hysteroscopy.

3. Endometrial biopsy.

Diagnostic hysteroscopy and endometrial biopsy were done only for:

a. Patients with abnormal uterine bleeding.Asymptomatic patients with endometrial thickness $>5 \mathrm{~mm}$ in postmenopausal or $>8 \mathrm{~mm}$ in premenopausal cases.

Data collected was tabulated and subjected to statistical analysis.

\section{- Patients were examined by}

A) TVUS evaluation: was performed using Voluson 730 Pro V GE unit (GE healthcare, Zipf, Austria) equipped with a multifrequency endovaginal transducer 4/7 MHz.

Sonographically, the endometrium should be measured from a sagittal or longaxis image of the uterus in the plane in which the endometrial stripe is seen contiguous with the endocervical canal and distinct from the myometrium .

Endometrial thickness was measured from the echogenic interface of the anterior basal layer to the echogenic interface of the posterior basal layer, thus representing a "double thickness".

Ultrasound assessment of group I showed some cases with cystically thickened endometrium under the effect of tamoxifen therapy.

\section{B) Diagnostic hysteroscopy:}

The hysteroscope used in this study was that of Karl Storz (Germany). It is a rigid continuous flow panoramic hysteroscopy 25 $\mathrm{cm}$ in length, $2.9 \mathrm{~mm}$ in diameter, with an outer sheath of $3.6 \mathrm{~mm}$ and a 30 degree fibrooptic lens.

The light source used in this study was a metal halide automatic light source from Circon Acmi G71A/Germany with a 150 Watt lamp. A fibro-optic cable is connected to the light source and to the hysteroscope.

The technique used to provide constant uterine distension was by attaching plastic bags of distilled water or saline bags to dual infusion tubing. Each bag was then wrapped in a pressure infusion cuff similar to that used in blood pressure to reach a pressure of $50-80$ $\mathrm{mmHg}$. The tubing was connected to the hysteroscope camera monitor. 


\section{Ahmed et al....}

Vaginoscopic approach was used; the tip of the hysteroscope was positioned in the vaginal introitus, the labia being slightly separated with fingers. The vagina was distended with saline. The scope was driven to the posterior fornix to readily visualize the portio and slowly backwards to identify the external cervical os. When this became visible, the scope was carefully moved forward to the external os and then the uterine cavity with least possible trauma.

Once the cavity was entered, a panoramic view of the uterine cavity to exclude uterine malformations or a deformed cavity. Examination should start systematically, first the fundus, anterior, posterior and lateral walls of the uterus ending by visualization of the uterotubal junctions.

At the end of the procedure, the hysteroscope was slowly withdrawn through the cervical canal which was visualized to detect any intracervical pathology and to observe the shuttering mechanism of the internal os.

After that, the scope was removed and the patient was asked to remain in the dorsal position for a few minutes to avoid vasovagal attack.

c) Endometrial biopsy: Pipelle or fractional curettage done by expert gynecologist for accurate diagnosis of endometrial lesions. Histopathological examination of group I showed some cases with dense stroma, fluid filled cystically dilated glands lined with flattened epithelium under the effect of tamoxifen therapy.

\section{Statistical Analysis}

Data were statistically described in terms and mean \pm standard deviation $( \pm \mathrm{SD})$. For comparing categorical data, chi Square(X2) test and Mann-Whitney U-test were performed. $\mathrm{P}$ value less than 0.05 were considered statistically significant. All statistical calculations were done using computer program SPSS (Statistical package for the Social Science, SPSS version 20.0).

\section{Zagazig University Medical Journals}

\section{RESULTS}

One hundred and seventeen breast cancer cases out of 120 cases completed study, as two cases escaped follow up and one case died.

As regard to clinical features of the study population, age was significantly higher in group II more than the other groups, majority of group I were premenopausal, while group II were postmenopausal. (Table 1)

Regarding endometrial thickness distribution among the studied groups, the mean endometrial thickness was $10.0 \pm 3.7$ in group I, $6.13 \pm 2.3$ in group II and $6.83 \pm 2.87$ in group III. Group I had significantly thicker endometrium than the other two groups. (Table 2)

In group I, the most common lesions detected by hysteroscopy were endometrial hyperplasia in 6 patients (37.5\%), polyp in 3 patients $(18.6 \%)$ and atrophy in 2 patients $(12.5 \%)$. The most common histopathological lesions of group I were endometrial hyperplasia in 5 patients $(31.3 \%)$, endometrial polyp in ₹ patients $(25 \%)$ and endometrial atrophy in two patient $(12.5 \%)$. According to endometrial biopsy findings, only one patient of group I showed endometrial hyperplasia with atypia. Group I showed 4 cases of cystic thick endometrium appearing on TVUS and diagnosed by histopathological examination. The most common histopathological lesions of group II were endometrial atrophy in 3 patients (30\%), endometrial polyp in one patient $(10 \%)$ and endometrial hyperplasia in one patient (10\%). Group III showed that the most common histopathological lesions were endometrial atrophy in one patient $(14.3 \%)$ ,endometrial polyp in one patient $(14.3 \%)$ and endometrial hyperplasia in one patient (14.3\%). (Tables 2,3,4,5)

Performance of ultrasonography and hysteroscopy in diagnosis of endometrial lesion in relation to biopsy findings showed that hysteroscopy was more sensitive and specific than ultrasonography in diagnosis of endometrial atrophy, hyperplasia and polyp. (Table 6) 
Table 1 Clinical features among the studied groups.

\begin{tabular}{|c|c|c|c|c|c|c|c|c|}
\hline & \multicolumn{2}{|c|}{ Group I No=40 } & \multicolumn{2}{|c|}{ Group II No=39 } & \multicolumn{2}{|c|}{$\begin{array}{c}\text { Group III } \\
\text { No=38 }\end{array}$} & $\mathbf{F}$ & $\mathbf{P}$ \\
\hline \multicolumn{9}{|l|}{$\operatorname{Age}(y)$} \\
\hline $\begin{array}{l}\text { Mean } \pm \text { SD } \\
\text { Range }\end{array}$ & \multicolumn{2}{|c|}{$\begin{array}{c}44.65 \pm 9.52 \\
27-65\end{array}$} & \multicolumn{2}{|c|}{$\begin{array}{c}55.42 \pm 8.69 \\
40-71\end{array}$} & \multicolumn{2}{|c|}{$\begin{array}{c}47.27 \pm 11.04 \\
27-65\end{array}$} & 13.139 & $0.00^{*}$ \\
\hline \multicolumn{9}{|l|}{ BMI (KG/M2) } \\
\hline $\begin{array}{l}\text { Mean } \pm \text { SD } \\
\text { Range }\end{array}$ & \multicolumn{2}{|c|}{$\begin{array}{c}31.5 \pm 3.4 \\
23-35\end{array}$} & \multicolumn{2}{|c|}{$\begin{array}{c}30.8 \pm 2.3 \\
25-35\end{array}$} & \multicolumn{2}{|c|}{$\begin{array}{c}33.5 \pm 1.8 \\
27-37\end{array}$} & 1.459 & 0.237 \\
\hline & No. & $\%$ & No. & $\%$ & No. & $\%$ & $\mathbf{X}^{2}$ & $\mathbf{P}$ \\
\hline \multicolumn{9}{|c|}{ Family history of breast cancer } \\
\hline -ve & 33 & 82.5 & 37 & 92.5 & 37 & 92.5 & \multirow[t]{2}{*}{2.76} & \multirow[t]{2}{*}{0.29} \\
\hline$+\mathrm{ve}$ & 7 & 17.5 & 3 & 7.5 & 3 & 7.5 & & \\
\hline \multicolumn{9}{|l|}{ Medical history } \\
\hline Medically free & 26 & 65.0 & 25 & 62.5 & 27 & 67.5 & 3.16 & 0.51 \\
\hline $\mathrm{DM}$ & 6 & 15.0 & 4 & 10.0 & 5 & 12.5 & & 0.81 \\
\hline HTN & 7 & 17.5 & 8 & 20.0 & 7 & 17.5 & & 0.70 \\
\hline Multiple disorders & 1 & 2.5 & 1 & 2.5 & 1 & 2.5 & & 0.89 \\
\hline \multicolumn{9}{|l|}{ Menopausal history } \\
\hline Post-menopausal & 7 & 17.5 & 28 & 71.8 & 16 & 42.1 & \multirow[t]{2}{*}{24.9} & \multirow[t]{2}{*}{$0.00^{*}$} \\
\hline Pre-menopausal & 33 & 82.5 & 11 & 28.2 & 22 & 57.9 & & \\
\hline
\end{tabular}

\section{SD: Standard deviation $\chi 2$ : Chi square test}

*: Highly significant $(\mathbf{P}<\mathbf{0 . 0 1})$

\section{LSD of Age distribution among studied groups:}

\begin{tabular}{|l|l|l|l|}
\hline & Group & Group & P \\
\hline & Group I & Group II & $0.00^{*}$ \\
\hline & Group I & Group III & 0.234 \\
\hline & Group II & Group I & $0.00^{*}$ \\
\hline & Group II & Group III & $0.00^{*}$ \\
\hline
\end{tabular}

*: Highly significant $(\mathbf{P}<0.01) \quad$ LSD: Least significant difference .

Table 2 Endometrial thickness distribution among studied groups.

\begin{tabular}{|l|c|c|c|c|c|}
\hline $\begin{array}{c}\text { Endometrial - } \\
\text { Thickness }\end{array}$ & $\begin{array}{c}\text { Group I } \\
\text { No=40 }\end{array}$ & $\begin{array}{c}\text { Group II } \\
\text { No=39 }\end{array}$ & $\begin{array}{c}\text { Group III } \\
\text { No=38 }\end{array}$ & F & P \\
\hline Mean \pm SD & $10.0 \pm 3.7$ & $6.13 \pm 2.3$ & $6.83 \pm 2.87$ & 11.030 & $0.00 *$ \\
Range (mm) & $4-24$ & $3-16$ & $5-18$ & & \\
\hline
\end{tabular}

LSD

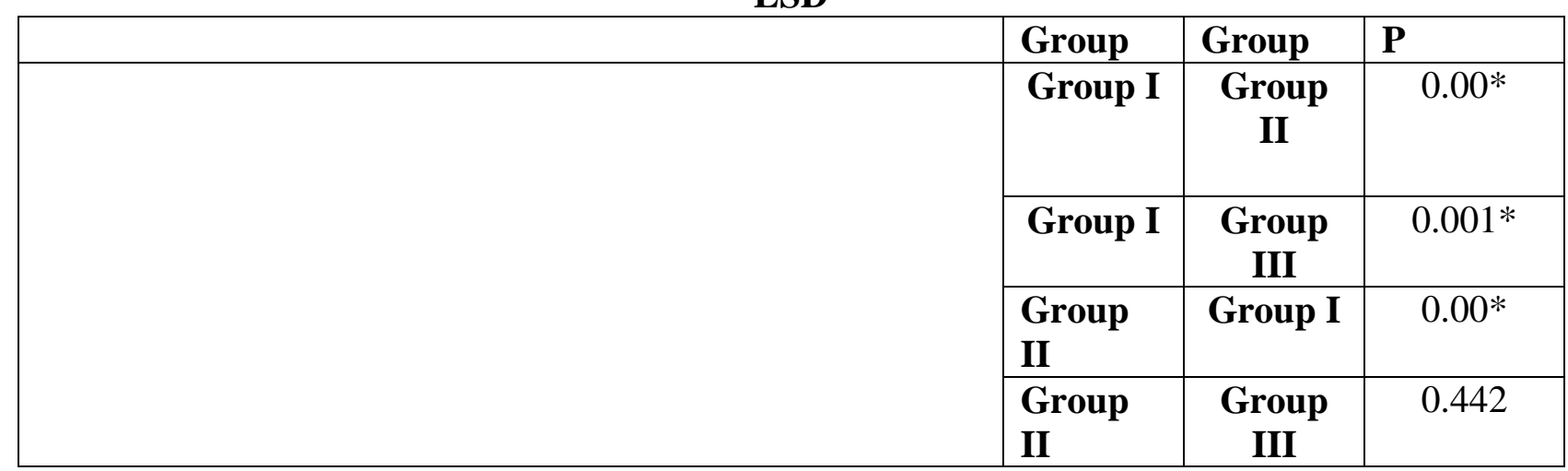

\section{*: Highly significant $(\mathbf{P}<0.01) \quad$ LSD: Least significant difference}


Table 3 TVUS finding among the studied groups after 6month of treatment.

\begin{tabular}{|c|c|c|c|c|c|c|c|c|}
\hline \multirow[t]{2}{*}{$\begin{array}{l}\text { Endometrium } \\
\text { thickness: }\end{array}$} & \multicolumn{2}{|c|}{ Group I No=40 } & \multicolumn{2}{|c|}{ Group II No=39 } & \multicolumn{2}{|c|}{$\begin{array}{c}\text { Group III } \\
\text { No=38 }\end{array}$} & \multirow[t]{2}{*}{$\mathbf{X}^{2}$} & \multirow[t]{2}{*}{$\mathbf{P}$} \\
\hline & No. & $\%$ & No. & $\%$ & No. & $\%$ & & \\
\hline $\begin{array}{l}\text { Normal thickness for Age and } \\
\text { Menopausal state. }\end{array}$ & 25 & 62.5 & 31 & 79.5 & 35 & 92.1 & 5.83 & $0.009 * *$ \\
\hline Abnormal thickness: & 15 & 37.5 & 8 & 20.5 & 3 & 7.9 & & \multirow[t]{5}{*}{$0.02 *$} \\
\hline Postmenopausal $>5 \mathrm{~mm}$ & 3 & 7.5 & 5 & 12.8 & 0 & 0.0 & & \\
\hline Premenopausal>8mm & 10 & 25.0 & 0 & 0 & 2 & 5.3 & & \\
\hline \multirow[t]{2}{*}{ Endometrial atrophy } & 2 & 5 & 3 & 7.7 & 1 & 2.6 & & \\
\hline & 3 & 7.5 & 2 & 5.2 & 1 & 2.6 & & \\
\hline $\begin{array}{l}\text { 3. polyp } \\
\text { Other associated U.S finding: }\end{array}$ & No. & $\%$ & No. & $\%$ & No. & $\%$ & & \\
\hline Adenomyosis & 0 & 0 & 1 & 2.6 & 1 & 2.6 & & 0.31 \\
\hline SMF & 0 & 0 & 1 & 2.6 & 1 & 2.6 & & \\
\hline
\end{tabular}

\section{$\chi 2$ : Chi square test $\quad *$ : Significant $(\mathbf{P}<0.05) \quad * *$ : Highly significant $(\mathbf{P}<0.01) \quad$ SMF: $($ sub} mucous fibroid).

Table 4: Hysteroscopic findings among the studied groups.

\begin{tabular}{|c|c|c|c|c|c|c|c|c|}
\hline \multirow[t]{2}{*}{$\begin{array}{c}\text { The hysteroscopic findings } \\
\text { : }\end{array}$} & \multicolumn{2}{|c|}{$\begin{array}{c}\text { Group I } \\
\text { No=16 }\end{array}$} & \multicolumn{2}{|c|}{$\begin{array}{c}\text { Group II } \\
\text { No }=10\end{array}$} & \multicolumn{2}{|c|}{$\begin{array}{c}\text { Group III } \\
\text { No=7 }\end{array}$} & \multirow[t]{2}{*}{$\mathbf{X}^{2}$} & \multirow[t]{2}{*}{$\mathbf{P}$} \\
\hline & No. & $\%$ & No. & $\%$ & No. & $\%$ & & \\
\hline Normal finding & 5 & 31.3 & 3 & 30 & 2 & 28.6 & \multirow[t]{6}{*}{12} & \multirow[t]{6}{*}{0.81} \\
\hline Polyp & 3 & 18.8 & 1 & 10 & 1 & 14.3 & & \\
\hline Endometrial atrophy & 2 & 12.5 & 3 & 30 & 1 & 14.3 & & \\
\hline Endometrial hyperplasia & 6 & 37.5 & 1 & 10 & 1 & 14.3 & & \\
\hline Others associated findings: & 0 & 0.0 & 1 & 10 & 1 & 14,3 & & \\
\hline SMF & 0 & 0.0 & 1 & 10 & 1 & 14.3 & & \\
\hline
\end{tabular}

\section{$\chi 2$ : Chi square test SMF:(sub mucous fibroid).}

Table 5: Endometrial biopsy findings of D\&C among the studied groups:

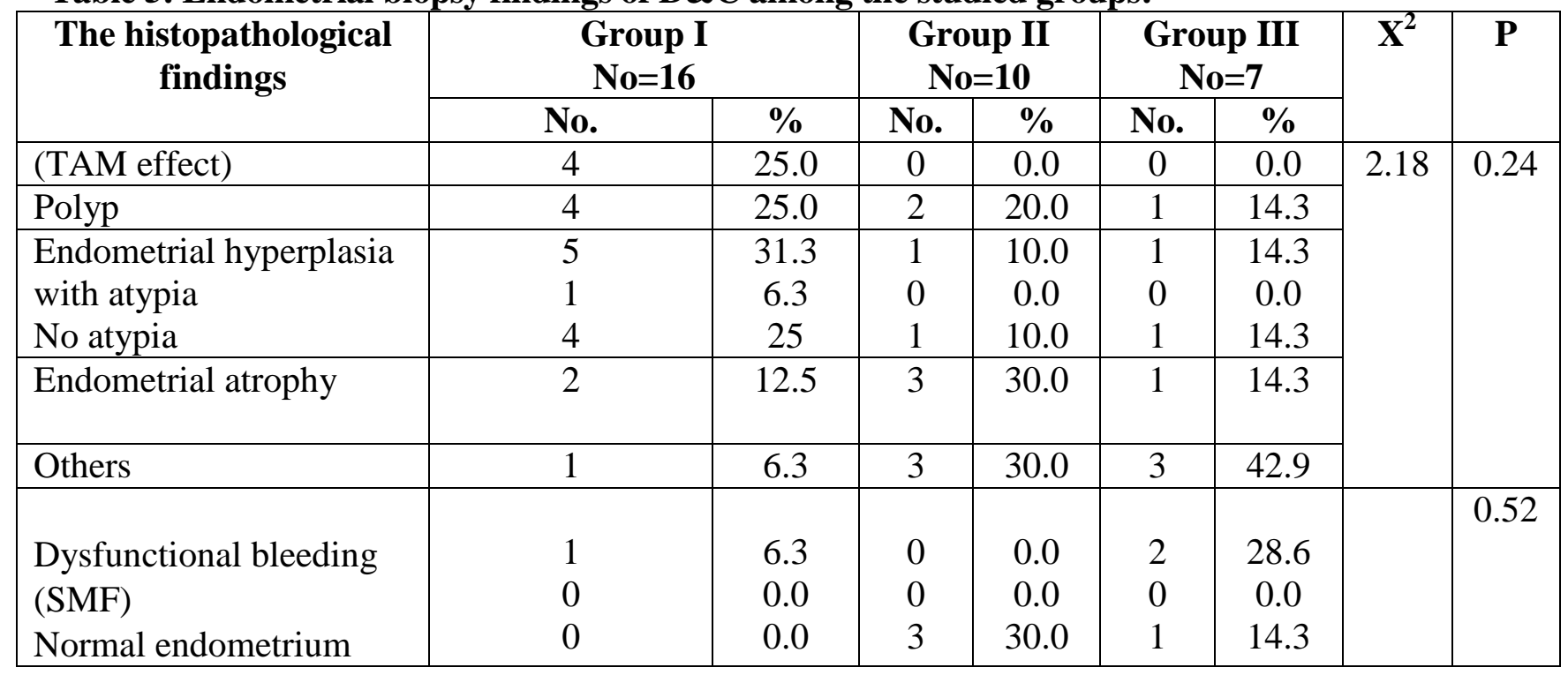

\section{$\chi 2$ : Chi square test SMF:(sub mucous fibroid).}


Ahmed et al....

Table 6: performance and Accuracy of ultrasonography and hysteroscopy in diagnosis of endometrial lesion in relation to biopsy findings:

\begin{tabular}{|l|l|l|l|l|l|l|}
\hline & & $\begin{array}{l}\text { Sensitivity } \\
(\boldsymbol{\%})\end{array}$ & $\begin{array}{l}\text { Specificity } \\
(\boldsymbol{\%})\end{array}$ & $\begin{array}{l}\text { PPV } \\
(\boldsymbol{\%})\end{array}$ & $\begin{array}{l}\text { NPV } \\
(\boldsymbol{\%})\end{array}$ & $\begin{array}{l}\text { Accuracy } \\
(\boldsymbol{\%})\end{array}$ \\
\hline \multirow{3}{*}{ US } & Hyperplasia & 85.7 & 72.4 & 42.9 & 95.5 & 75 \\
\cline { 2 - 7 } & Atrophy & 80 & 83.9 & 44.4 & 96.3 & 83.3 \\
\cline { 2 - 7 } & Polyp & 66.7 & 90.3 & 57.1 & 93.3 & 86.5 \\
\hline \multirow{3}{*}{ Hysteroscopy } & Hyperplasia & 85.7 & 95.8 & 85.7 & 95.8 & 93.6 \\
\cline { 2 - 7 } & Atrophy & 100 & 80.8 & 50 & 100 & 83.9 \\
\cline { 2 - 7 } & $\begin{array}{l}\text { Endometrial } \\
\text { polyp }\end{array}$ & 80 & 92.3 & 66.7 & 96 & 90.3 \\
\hline
\end{tabular}

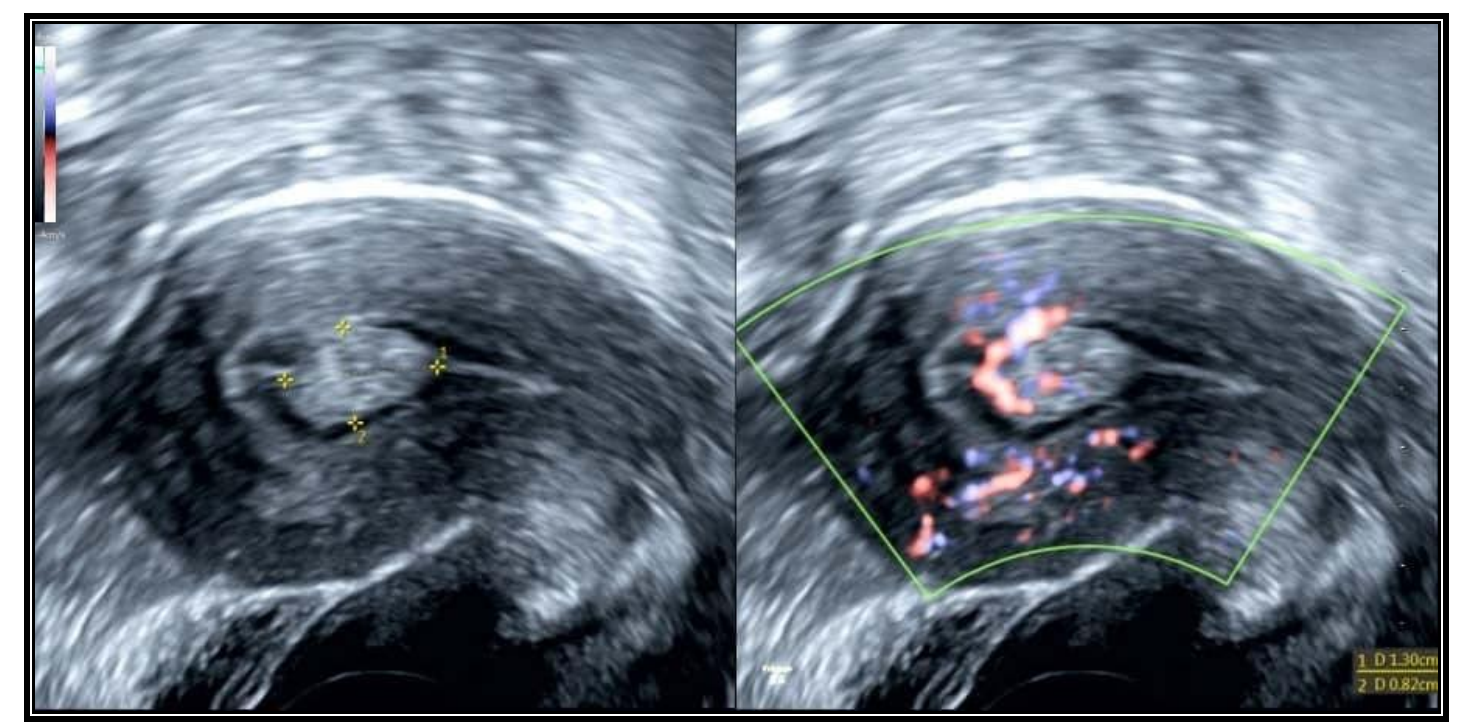

a

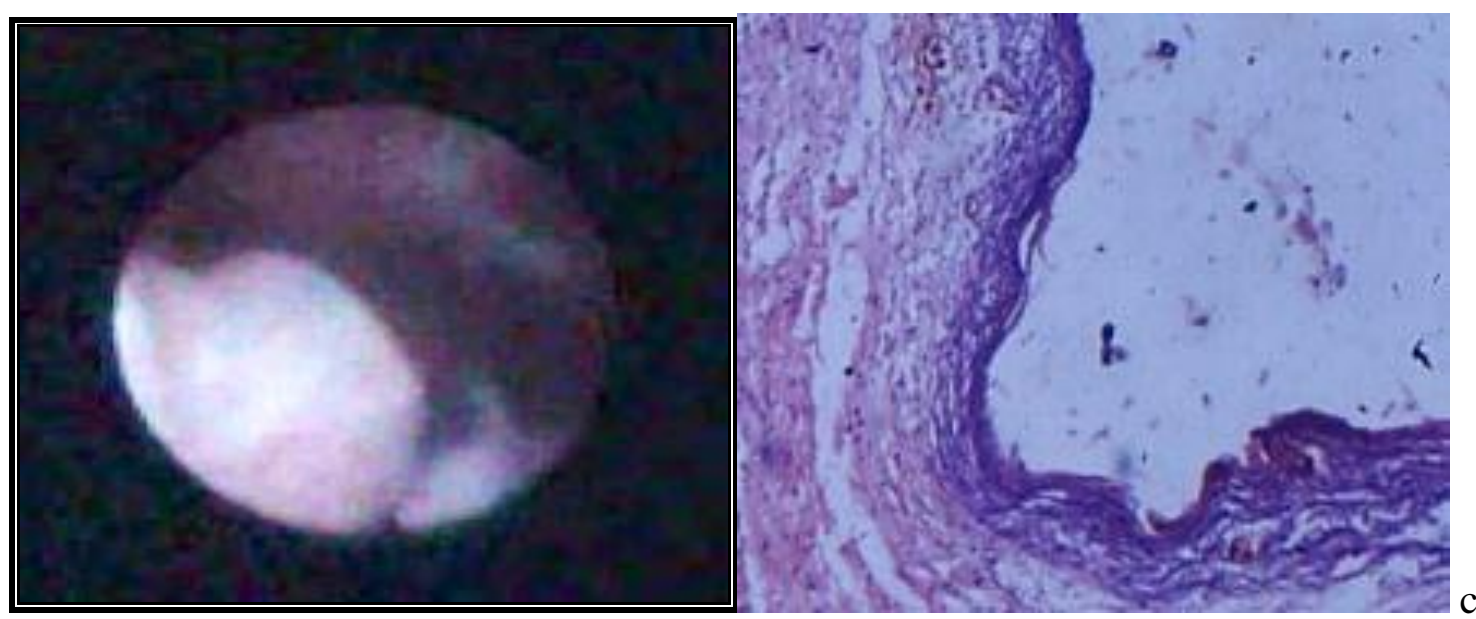

B

Figure (7)

a-TVUS showing endometrial polyp .

b-hysteroscopy showing endometrial polyp .

c-Histopathological examination of endometrial polyp. . 


\section{DISCUSSION}

Worldwide, breast cancer accounts for approximately $25 \%$ of all cancers diagnosed in women. In Egypt, breast cancer is estimated to be the most common cancer among females accounting for $37.7 \%$ of females' all cancers and the leading cause of death accounting for $29.1 \%$ of cancer -related mortality (7).

In the current study, there was a highly significant difference of the mean endometrial thickness among the three groups, so that group I had significantly thicker endometrium than in the other two groups and this was in agreement with the results of Le Donne et al study as they reported a mean endometrial thickness, as evaluated by TVUS, of $7.7 \mathrm{~mm}$ in the TAM group, $6 \mathrm{~mm}$ in the AIs group and $4.8 \mathrm{~mm}$ in the NT group. There was a significant difference between the 3 groups with thicker endometrium in TAM group than the other two groups. (8)

The results of the current study also were comparable to the results of Kim et al study as they found that in women received tamoxifen, the endometrium was continuously thickened in proportion to the duration of the therapy while it remained unchanged in women receiving anastrozole. (9)

In the current study, ultrasound assessment of group I showed 4 cases with cystically thickened endometrium under the effect of Tamoxifen therapy and this agreed with results of Le Donne et al study as they found TAM-induced cystically thickened endometrium revealed by ultrasound.(8) Also the results were in accordance with the results of Valenzano et al who found that cystic endometrial appearance was more frequent in patients under tamoxifen than in those under anastrozole $(\mathrm{p}<0.001)$. (10)

TVUS assessment of group II In the current study, showed 4 cases shifted to AIs After TAM treatment with reduction of mean endometrial thickness and this was in accordance with Gerber et al study, as they investigated the effect of switching from adjuvant tamoxifen to anastrozole (aramidex) treatment in postmenopausal women with endocrine-responsive breast cancer .The mean endometrial thickness for patients who switched to anastrozole was significantly reduced compared with those who continued tamoxifen treatment $(\mathrm{P}<0.0001)$.(11) Our results were comparable to Valenzano et al who found that anastrozole reverses tamoxifen-induced increased endometrial thickness and sonographic endometrial cystic appearance.(10)

In the current study, TVUS showed a sensitivity of $85.7 \%$, specificity of $60.0 \%$ and this agreed with Gerber et al who showed that TVUS was not accurate in identifying hyperplasia and polyps, as endometrial thickness measurements missed hyperplastic changes and polyps in a large number of cases. Furthermore, for intracavitary lesions, TVUS was unable to differentiate between a polyp, which may contain cancerous cells, and endometrial atrophy. (11)

In the current study, hysteroscopic findings in group I was in agreement with the results of Saccardi et al who investigated the endometrium of 151 TAM users with hysteroscopy and histopathology. Endometrial polyps were the most commonly diagnosed pathologies in TAM-treated patients, especially in post-menopausal women $\{6$ cases $(4 \%)\}$. (12)

In the current study, results of hysteroscopic examination regarding the endometrial lesions in group II agreed with Gerber et al as they compared patients on anastrazole (83 patient) with those on tamoxifen (88 patient). Hysteroscopic examination revealed that the most common endometrial lesion of anastrozole group was atrophy in 4 cases $(4.8 \%)$ and the most common endometrial lesions of tamoxifen group were $\{14$ polyps $(16 \%)$ and 8 hyperplasias $(9 \%)\}$. (10)

In the current study, hysteroscopy was more accurate in the diagnosis of endometrial lesions than ultrasonography and this agreed with the results of Le Donne et al study who showed that there was a significant correlation between hysteroscopic and histological findings with regard to the diagnosis of endometrial atrophy, polyps, hyperplasia and cancer $(\mathrm{P}<0.001)$.It is the only method that provides a direct view of the endometrial cavity and the possibility of performing directed biopsies for a definitive diagnosis. (8) 


\section{Ahmed et al....}

Results of the current study, regarding lesions detected by histopathological examination in cases of group I, were in agreement with Kavak' et al study, as they found that the most common histopathologic finding was endometrial polyp, detected in five patients $(9.1 \%)$ with Tamoxifen therapy. In the control group there was no endometrial polyps. (13)

Also the results were comparable to that of Ascher et al who showed that the most common histopathologic finding with Tamoxifen treatment was endometrial polyp. (14)

Regarding atypical endometrial
hyperplasia associated with tamoxifen treatment in group I, this agreed with the results of Saccardi et al research as they found only one case with endometrial glandular atypia (2.6\%).(12) This was comparable with the incidence of endometrial hyperplasia with atypia in the general population reported by Ascher et al (14)

However, results of histopathological examination in group I were not in agreement with Exacoustos et al study * as they studied 38 asymptomatic postmenopausal women. All had been treated with tamoxifen (20-30 $\mathrm{mg} /$ day) for breast cancer for at least 1 year. Thirty asymptomatic postmenopausal women (control group) and 25 asymptomatic postmenopausal breast cancer patients on tamoxifen therapy (tamoxifen group).Nineteen benign endometrial polyps $(50 \%)$ were found. And four endometrial hyperplasias $(10.5 \%)$. The non-agreement with the current study was due to different sample size and shorter duration of follow up. (15)

The previous published research by Seul et al was in agreement with the current study as they retrospectively reviewed the medical records of 309 women with breast cancer who were currently receiving tamoxifen and undergoing regular gynecological examination. The prevalence of endometrial thickening was $12 \%$ in the preand $10.6 \%$ in the postmenopausal group. An endometrial biopsy was performed in 43 women and confirmed endometrial cancer in one case $(2.3 \%)$, endometrial polyps in 14

\section{Zagazig University Medical Journals}

cases $(32.56 \%)$, and endometrial hyperplasia in 4 cases $(9.3 \%) .(16)$

The current study also showed that the endometrial lesions detected by histopathological examination of group II revealed 3 patients $(30 \%)$ with endometrial atrophy, two patients $(20 \%)$ with endometrial polyp and one patients (10\%) with endometrial hyperplasia. Thus the commonest endometrial lesion of group II was endometrial atrophy. This agreed with the results of Gerber et al study as they compared patients on Anastrazole with those on tamoxifen. Histopathologic examination revealed that the most common endometrial lesion was atrophy in $(4.8 \%)$ of anastrozole group, while the most common endometrial lesions in the tamoxifen group were polyps (16\%), hyperplasia (9\%) and 7 atrophies (8\%). (11)

In conclusion, this study suggested that Tamoxifen was associated with development of various endometrial changes, including endometrial hyperplasia, cystic atrophy, leiomyoma, endometrial carcinoma, and other types of uterine malignancy especially in postmenopausal patients. Even if they are asymptomatic, these patients must be evaluated carefully. Transvaginal ultrasonography, dilatation and curettage (D\&C) and hysteroscopy have been used in the examination of tamoxifen-treated women with increased endometrial thickness $(\geq 5 \mathrm{~mm})$ in postmenopausal and $(\geq 8 \mathrm{~mm})$ in premenopausal women.

Conflict of Interest: Non declared.

Funding: No funding sources

\section{REFERENCES}

1.Jemal A.; Bray F.; Center MM.; et al., (2011): Global cancer statistics. CA Cancer J Clin; 61: 69.

2.Early Breast Cancer Trialists' Collaborative Group (EBCTCG) (2005): Effects of Chemotherapy and Hormonal Therapy for Early Breast Cancer on Recurrence and 15-year Survival: an Overview of the Randomised Trials. Lancet; 365 (9472): 1687-717.

3.Coates, A. S.; Keshaviah, A.; Thurlimann, B.; et al., (2007): Five years of letrozole compared with tamoxifen as initial adjuvant therapy for postmenopausal women with endocrine- 
Ahmed et al....

responsive early breast cancer: update of study BIG 1-98. Journal of clinical oncology; 25(5): 486-492.

4.Goldhirsch A.; Wood WC.; Gelber RD.; et al., (2007): Progress and promise: highlights of the international expert consensus on the primary therapy of early breast cancer. Ann Oncol; 18:1133-44

5.Paridaens RJ.; Dirix LY.; Beex LV.; et al., (2008): Phase III study comparing exemestane with tamoxifen as first-line hormonal treatment of metastatic breast cancer in postmenopausal women: the European Organisation for Research and Treatment of Cancer Breast Cancer Cooperative Group. J Clin Oncol; 26:4883-90.

6.Forbes, J.F.; Cuzick, J.; Buzdar. A.; et al., (2008): Effect of anastrozole and tamoxifen as adjuvant treatment for early-stage breast cancer: 100-month analysis of the ATAC trial. Lancet Oncol; 9:45-50.

7.Zeeneldin A.A.; Saber M.M.; El-Din I.A.S.; et al., (2013): Clinico-pathological features of breast carcinoma in elderly Egyptian patients: A comparison with the non- elderly using population-based data.Journal of the Egyptian National Cancer Institute; Volume 25, Issue 1, Pages 5-11.

8.Le Donne M.; Alibrandi A.; Ciancimino L.; et al., (2013): Endometrial pathology in breast cancer patients: Effect of different treatments on ultrasonographic, hysteroscopic and histological fndings. Oncology Letters; 5: 1305-10.

9.Kim HS .; Jeon YT.; Kim YB .; (2008). The effect of adjuvant hormonal therapy on the endometrium and ovary of breast cancer patients . J Gynecol Oncol. 2008 Dec;19(4):256-

60.doi10.3802/jgo.2008.19.4.256. Epub 2008 Dec 29.

10.Valenzano Menada M.; Costantini S.; Moioli M.; et al., (2008): Evaluation of endometrial thickness in hormone receptor positive early stage breast cancer postmenopausal women switching from adjuvant tamoxifen treatment to anastrozole. Breast.;17:631-636.

11. Gerber, B.; Krause, A.; Muler, H.; et al., (2005): Effects of adjuvant tamoxifene on the

\section{Zagazig University Medical Journals}

endometrium in postmenopausal women with breast cancer: a prospective long-term study using transvaginal ultrasound. J Clin Oncol; 18: 3464-70.

12.Saccardi c; Salvatore Gizzo;Tito Silvio et al.,(2012): Endometrial surveillance in tamoxifen users: role, timing and accuracy of hysteroscopic investigation: observationallongitudinal cohort studyDepartment of Woman and Child Health, U.O.C. di Ginecologia e Ostetricia, University of Padua, Via Giustiniani 3,35128 Padua, ItalyDepartment of Surgical Sciences, University of Parma, Parma, Italy.

13.Kavak ZN.; Binöz S.; Ceyhan N and Pekin (2000): The effect of tamoxifen on the endometrium, serum lipids and hypothalamus pituitary axis in the postmenopausal breast cancer patients. PMID: 10929963,Acta Obstet Gynecol Scand. Jul; 79(7):604-7.

14.Ascher, S. M.; Imaoka, I. and Lage, J. M. (2000): Tamoxifen-induced uterine abnormalities: the role of imaging. Radiology; 21(1): 29-38.

15.Exacoustos C ;Zupi E; Cangi B;etal.,(2012) ; Endometrial evaluation in postmenopausal breast cancer patients receiving tamoxifen: an ultrasound, color flow Doppler, hysteroscopic and histological study. 8903921[PubMed indexed for MEDLINE] edited by 2 PubMed Central articles Review Surgical Management of Endometrial Polyps in Infertile Women: A Comprehensive Review.[Surg Res Pract. 2015 Correlation between Blood Flow Signal of Color Flow Imaging and Nottingham Prognostic Index in Patients with Breast Carcinoma.[Breast Care (Basel). 2012.

16.Seul Lee, Yun Hwa Kim, Seung Chul Kim et al .,(2018): The effect of tamoxifen therapy on the endometrium and ovarian cyst formation in patients with breast cancerObstet Gynecol Sci. 2018 Sep; 61(5): 615-620. Published online 2018

Aug 13. doi: [10.5468/ogs.2018.61.5.615].PMCID: PMC6137019PMID: 3025499

How to cite this article: Ahmed AA; Nashwa EN; Amr AE; Manal AA.Effects Of Tamoxifen And Aromatase Inhibitors On Endometrium In Breast Cancer Patients At Zagazig University Hospitals..ZUMJ 2019; 25 (2); 269-277. DOI: 10.21608/ZUMJ.2019.26413 